\title{
Proceeding
}

Supplementary Issue: Winter Conferences of Sports Science. Costa Blanca Sports Science Events, 24 April 2020. Alicante, Spain.

\section{Test design to measure the cognitive processing speed of table tennis players}

\author{
ZAHRAA ZAALAN MOHSEN , FATIMA ABDUL MALEH \\ College of Physical Education and Sports Science for Girls, Baghdad University, Iraq
}

\begin{abstract}
Table tennis is considered one of the fast base sports that the player needs to have the speed of performance and awareness, especially in straight forward and back strikes, which is an important offensive skills, and the player success depends on his perception speed to the point of the fall of the ball in the arena of his competitor. But there is no way to measure cognitive processing speed. Therefore, the researchers sought to design a test that measures this ability to ensure its scientific evaluation, and then establish standard scores for this test for the players of the specialized school of table tennis, to help evaluate them objectively and move away from subjective estimates when evaluating and developing measuring instruments in the field of table tennis. The descriptive curriculum was adopted on the 46 players of the table tennis school. After the exploratory experiment was conducted and confirmed the test validity and the availability of scientific specifications, it was applied to the sample taking into account all legal procedures during the implementation of the final test and then collected the results and was discharged and processed statistically, and the researchers concluded: The test designed proved to be valid for measuring cognitive processing speed. The research sample achieved a higher percentage at an acceptable and average level, respectively. So, the researchers recommend using the test designed to measure cognitive processing speed.
\end{abstract}

Keywords: Test design; Cognitive processing speed; Table tennis.

\section{Cite this article as:}

Mohsen, Z.Z., \& Maleh, F.A. (2020). Test design to measure the cognitive processing speed of table tennis players. Journal of Human Sport and Exercise, 15(2proc), S154-S161. doi:https://doi.org/10.14198/ihse.2020.15.Proc2.05

Corresponding author. College of Physical Education and Sports Science for Girls, Baghdad University, Iraq.

E-mail: dr.ghafarsaeedissa@gmail.com

Supplementary Issue: Winter Conferences of Sports Science. Costa Blanca Sports Science Events, 24 April 2020. Alicante, Spain.

JOURNAL OF HUMAN SPORT \& EXERCISE ISSN 1988-5202

(c) Faculty of Education. University of Alicante

doi:10.14198/jhse.2020.15.Proc2.05

S154 | 2020| Proc2 | VOLUME 15

C 2020 University of Alicante 


\section{INTRODUCTION}

The training process has made great strides forward in our modern era, relying on the use of evaluation and measurement methods, which had an effective role in diagnosis, classification, prediction, selection, guidance, and has become an important and reliable basis in the planning of sports training, and one of the rules on which the training process is based. Therefore, all sports professionals should strive to develop sports events by finding tests through which players can be recognized and building a strong base. Tests are often used in the sports field and it has an undoubtable benefit and the tests may be designed to measure many abilities, skills, general and special preparations, as well as mental and psychological aspects. The effective use of tests in the field of physical education depends on several factors, including the level of sophistication of the test paper and its relationship to other sciences, and the lack of appropriate tests for learners limits the development of sporting events. \# One of the basic requirements needed by the table tennis player is the availability of cognitive processing speed which is a mental process which must be taken into consideration when training or selecting players as it helps to achieve the right path to the front and back strikes associated with the sense of sight, which contributes to Develop accuracy in the performance of straight forward and rear strikes. Therefore, the player of table tennis must have the speed of perception and ability to understand the opponent in his strength and weakness and the speed of understanding positions to make the right decision at the right time and place to respond to his strikes. Therefore, coaches most seek to gain the player's motor qualities and crystallize them in the development of cognitive processing speed and accuracy of the performance of straight forward and back strokes in table tennis. Hence, the researchers sought attention to cognitive processing speed through the design of their test, which gives the correct motor behaviour of the ball tracks and therefore the accuracy required in the fall of the ball on the table with the speed of performance, and this is reflected in the accuracy of the skilled performance of offensive strokes in table tennis.

\section{The research problem}

In order to achieve advanced results in table tennis, we must stand at points that have not been noticed by the coaches and which are important in scoring points for table tennis, which must be possessed by each player and can be developed according to the correct scientific basis. By following the training of table tennis in the specialized school, the researchers sought to find a practical mathematical test away from the paper and pen suitable for the motor performance in table tennis to measure cognitive processing speed, and then set standard scores for this test for the players of the specialized school in table tennis, to help evaluate them objectively and move away from self-assessment when evaluating and developing measuring instruments in the field of table tennis.

\section{The research goals}

- Test design to measure cognitive processing speed for table tennis.

- Setting standard scores and levels for this test for players in the specialized school of table tennis.

\section{The research impose}

The test designed is valid to measure the cognitive processing speed in table tennis.

\section{The research fields}

Human field: 46 players in the specialized school of table tennis. Time domain: 15-12-2019 to 11-1-2020. Spatial area: National Center for The Welfare of Sports Talent in table tennis, Youth City, Ministry of Sports and Youth. 


\section{MATERIAL AND METHODS}

\section{Procedures}

The descriptive approach has been adopted for its suitability and the nature of solving the research problem.

\section{Participants}

The research community was identified as the 46 players of the specialized school who were $10-18$ years old and represented the sample by $100 \%$.

\section{Measures}

- Arab and foreign references.

- Internet.

- A questionnaire for experts and specialists on the validity of the test.

- Legal table court + table tennis rackets.

- Legal table balls coloured 5 colours (orange-red-green-blue-yellow)

- Special ball thrower in table tennis.

- Stopwatch.

- Metric measuring tape.

\section{Statistical means}

Statistical laws were used in accordance with the statistical system (SPSS):

1- Arithmetic mean. 2. Standard deviation. 3- Medium. 4- Range. 5- Coefficient Of skewness. 6- Simple correlation coefficient. 7- Percentage. 8. Standard grade. 9 - Adjusted standard grade.

\section{RESULTS}

The natural distribution and suitability of the test was confirmed for the research sample represented by the players of the specialized school of table tennis, where the sample is considered a natural distribution if the level of skewness is limited between $( \pm 1)$,as shown in Table 1.

Table 1. The natural distribution of the research sample shows the cognitive speed test in table tennis.

\begin{tabular}{lccccccc}
\hline $\begin{array}{l}\text { Testing the } \\
\text { cognitive } \\
\text { processing speed } \\
\text { of table tennis }\end{array}$ & $\begin{array}{c}\text { Arithmetic } \\
\text { mean }\end{array}$ & $\begin{array}{c}\text { Standard } \\
\text { deviation }\end{array}$ & Medium & Range & $\begin{array}{c}\text { Highest } \\
\text { value }\end{array}$ & $\begin{array}{c}\text { Lowest } \\
\text { value }\end{array}$ & $\begin{array}{c}\text { Skewness } \\
\text { coefficient }\end{array}$ \\
\cline { 2 - 7 } & 15.08 & 8.14 & 14 & 28 & 30 & 2 & .48 \\
\hline
\end{tabular}

The raw scores for the cognitive speed test in table tennis have been converted into standard and modified standard grades, as shown in Table 2.

Table 2. Shows rough, standard, adjusted and repeat grades to test the cognitive processing speed of table tennis.

\begin{tabular}{cccc}
\hline Rough grades & Standard grades & Adjusted standard grades & Repeat \\
\hline 2 & -1.70 & 33.05 & 1 \\
3 & -1.57 & 34.28 & 2 \\
4 & -1.45 & 35.50 & 1 \\
5 & -1.33 & 36.73 & 2 \\
\hline
\end{tabular}




\begin{tabular}{cccc}
\hline 6 & -1.20 & 37.96 & 1 \\
8 & -0.96 & 40.42 & 1 \\
9 & -0.84 & 41.65 & 1 \\
10 & -0.71 & 42.87 & 8 \\
11 & -0.59 & 44.10 & 3 \\
13 & -0.34 & 46.56 & 2 \\
14 & -0.22 & 47.79 & 3 \\
15 & -0.10 & 49.02 & 2 \\
16 & 0.02 & 50.25 & 2 \\
17 & 0.15 & 51.47 & 2 \\
18 & 0.27 & 52.70 & 3 \\
20 & 0.52 & 55.16 & 1 \\
22 & 0.76 & 57.62 & 3 \\
28 & 1.50 & 64.99 & 4 \\
30 & 1.74 & 67.44 & 4 \\
\hline
\end{tabular}

Table 3. Shows the standard grades and levels of the cognitive processing speed test in table tennis.

\begin{tabular}{lllcr}
\hline Standard grades & Rough grades & Level & Test subject number & Percentage \\
\hline From -1.33 and below & From 5 and below & Weak & 6 & $13.08 \%$ \\
From (-0.71) to (-1.2) & From 6 to 10 & Acceptable & 11 & $23.98 \%$ \\
From (-0.1) to (-0.59) & $15-11$ & Average & 10 & $21.76 \%$ \\
From (0.02) to (0.52) & $20-16$ & Good & 8 & $17.44 \%$ \\
From (0.76) to (1) & $25-21$ & Very good & 3 & $6.30 \%$ \\
From 1.5 and above & 26 and above & Excellent & 8 & $17.44 \%$ \\
\hline & & Total & 46 & $100 \%$ \\
\hline
\end{tabular}

\section{Cognitive processing speed test}

After looking at the sources and references, The researchers found tests of cognitive processing speed in the field of psychological and educational sciences, which is the tests of paper and pen, as well as the existence of tests of cognitive processing speed through the system of FINA, and both tests are the perception of shapes and distances in a specific time. It is far from the sporting field, particularly table tennis, so the test was designed and codified to the research community after conducting scientific foundations on the test.

\section{Test description}

Test name: cognitive processing speed for table tennis players. The purpose of the test: to measure the cognitive processing speed of table tennis. Used tools: legal table playground, Table tennis rackets, Coloured legal table balls (5) colours (orange-red-green-blue-yellow), A special ball thrower in table tennis is installed against the lab player, and Stopwatch.

\section{Test method}

Divides the table playground or opposite the side of the test subject according colours and longitudinally (5 colours and evenly).

The test subject stands on one side of the table and the device on the other side. The device works when the start signal is given by the researcher by turning the device on which throws the balls at a rate of 25 balls within 25 seconds and randomly in terms of direction and colour, the player has to respond to those coloured 
balls by striking it to the coloured part of the table playground with the same colour of the ball so that the colour of the ball is perceived and hit towards the colour on the table. Each colour has five balls fired randomly.

\section{Scoring method}

The number of times the ball is hit correctly in the opponent's yard is calculated within a time of 25 seconds. So that the coloured ball is on the same coloured area. The highest score in the test is 50 degrees and the lowest score is zero. Grades are calculated by:

- If the ball is struck and falls on the wrong colour of the opponent's yard, a single score is given.

- If the ball is struck and falls on the area in the same colour, two degrees is given.

- If the ball is struck and falls out of the table or it was not missed, zero is given.

The more balls the test subject hits correctly which has the same colour as the ball, the more he shows possession of cognitive processing speed. Figure 1 illustrates this:

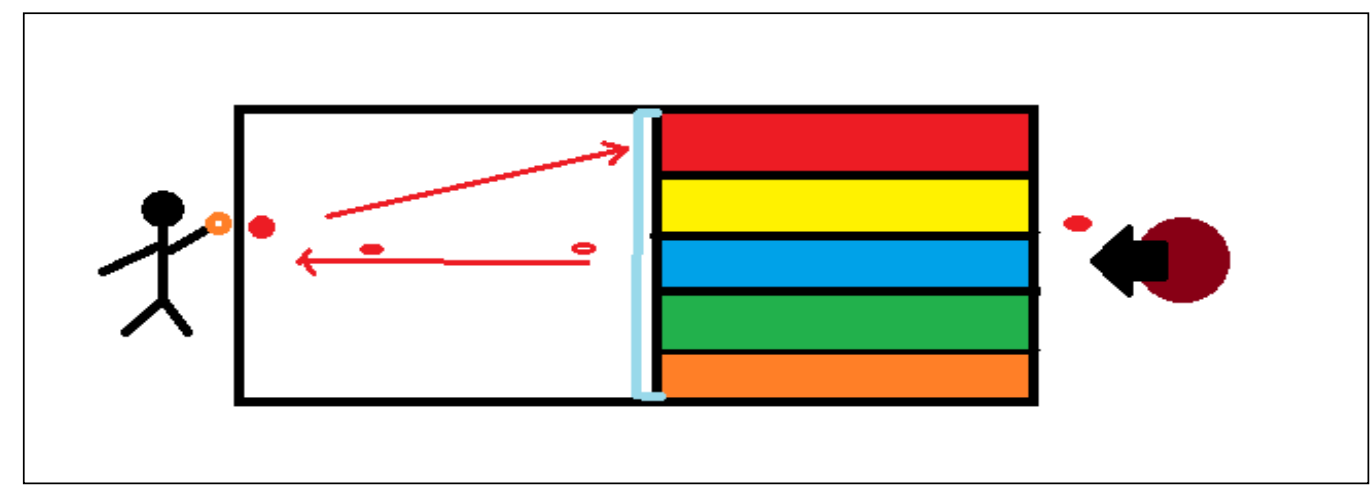

Figure 1. Drawings of the cognitive processing speed test in table tennis.

\section{Test scientific bases}

After preparing for a final test, the scientific bases were conducted according to the following:

Test honesty (honesty of experts)

The test was presented to a number of (10) experts in table tennis, testing and measurement, for the purpose of evaluating it and judging its validity. "We can count the test as honest if it is presented to a number of specialists and experts in the field that the test measures and they rule that it measures what is put in place to measure it efficiently"1.

A minimum of $75 \%$ has been adopted for the expert opinion about the test validity, Benjamin asserts that "The researcher has to obtain approval of $75 \%$ or more of the opinions of experts in this type of honesty"2, the test achieved an agreement rate of $(100 \%)$.

\footnotetext{
${ }^{1}$ Karajeh,A.(1997). Measurement and evaluation in psychology, a new vision: Dar Al-Bazouri Scientific Publishing and Distribution, Amman.

2 Bloom,B. \& et al(1983). Evaluate the student's formative and formative learning. Muhammad Amin Al-Mufti and others: Dar AlHikma McGr and Hill Publishing.
} 


\section{Distinctive power}

Table 4. Test distinctive power.

\begin{tabular}{|c|c|c|c|c|c|c|c|}
\hline \multirow{3}{*}{$\begin{array}{l}\text { Testing the } \\
\text { cognitive } \\
\text { processing } \\
\text { speed of } \\
\text { table tennis }\end{array}$} & $\begin{array}{l}\text { Measurement } \\
\text { unit }\end{array}$ & Sample & $S$ & $\pm p$ & T-Test & Sig. & $\begin{array}{l}\text { Significance } \\
\text { differences }\end{array}$ \\
\hline & & Non- players & 1.14 & .69 & \multirow[b]{2}{*}{5.77} & \multirow[b]{2}{*}{.000} & \multirow[b]{2}{*}{ Significan } \\
\hline & Frequency & $\begin{array}{l}\text { Table tennis } \\
\text { players }\end{array}$ & 3.42 & .78 & & & \\
\hline
\end{tabular}

Note: Significant at a level of $\leq .05$.

Distinctive power was performed on a randomly selected sample 24 players from the research community. After the test was carried out, the difference between high-grade players and low-grade players in table tennis was found, By taking (27\%) From the highest grades and (27\%) from the lowest grades and finding the difference between them on 15-12-2019. As shown in Table 4.

\section{Test stability}

Stability: means the degree of consistency and accuracy that the measurement method can use in order to measure the subject of the measurement ${ }^{3}$. The method of retesting was used after a time interval on the test preparation sample on the day of 15-12-2019 and they were 24 players. The test was retested again after 7 days on 22-12-2019, and between the two tests the simple correlation coefficient (Pearson) was conducted, showing that the value of the calculated correlation coefficient was (.87) and the probability of an error was $(.000)$ at a significant level of (.05), The test is therefore highly stable because the value is less than the error probability of error.

\section{Objectivity}

Objectivity: Means that the estimated ones do not differ in judging something. Therefore, objectivity was performed by recording the sample results in the first test of stability by researchers and then the simple correlation coefficient (Pearson) was conducted between the two tests showing that the value of the calculated correlation coefficient was (.99) and the probability of an error was (.000) at the level of significance (.05), therefore the test is highly stabile because the value is less than the error probability of error.

\section{Exploratory experiment}

The survey was conducted on 5-1-2020 on (4) randomly selected players from the research community, and the goal of the survey experiment was to identify the constraints that may arise during the test and to identify the validity of the devices and tools used in the search.

\section{Experiment procedures}

After the exploratory experiment was conducted and confirmed the validity of the test and the availability of scientific specifications, it was applied to the research sample of (46) players on 11-1-2020 taking into account all legal procedures during the implementation of the final test, and then the results were collected and discharged and processed statistically.

\section{DISCUSSION}

Table 4 shows that the sample of the research concentrated its repetitions at the acceptable and average level, which achieved a ratio of $(23.98 \%$ and $21.76 \%)$ respectively. The table tennis player needs to use good

${ }^{3}$ Farhat,L.(2002). Mathematical Cognitive Measurement. ed 1. Cairo: the Book Center for Publishing. 
cognitive movements in coordination with the work of the nervous system to integrate and implement movements of different types at high speed, and in line with skilled performance, because the movements of the player in general are characterized by a small and precise motor range of performance. Cognitive processing speed is therefore one of the determinants that should be taken into consideration for a table tennis player. An individual cognitive processing speed requires speed and accuracy in visual detail between similarity and differences in colours or shapes ${ }^{4}$. This corresponds to the nature of the designed test, which requires speed, accuracy by the player to match the colour of the ball with the colour of the place its fall on, in fractions of a second. The standardized tests are a means of evaluation in the field of sports, which gives the trainers great benefits to enable them to raise the efficiency of the training process, by recognizing the raw values, standard grades and sample level in the cognitive processing speed of table tennis. Cognitive processing speed indicates the ability of the individual to perceive motor positions in a single pictorial framework and issue the decision accurately and at high speed and match the shapes, colours or positions to serve the desired goal ${ }^{5}$. This applies to the cognitive processing speed of table tennis players. Mohammed emphasizes the importance of evaluation in sports training, its active role in programs, the extent to which it is achieved for the purposes set, and its importance in identifying weaknesses in individuals, or in programs, and determining the extent of progress, the state of the individual training, its characteristics are motor, mental and social 6 . The tests that are built and codified on samples representing the beneficiary community are more appropriate than others that have been built and codified on samples representing another community, no matter how similar they may be?

\section{CONCLUSION}

1. The test designed to measure the cognitive processing speed of table tennis.

2. Standard grades and levels of cognitive processing speed testing were concluded and in table tennis.

3. The research sample achieved a higher percentage at an acceptable and average level respectively.

\section{Recommendations}

1. Use the test designed to measure cognitive processing speed in table tennis.

2. Use the standard grades and levels shown by the results of this study to evaluate table tennis players.

\section{REFERENCES}

Abdel-Hafez,T. (2016). Attention control, working memory, and cognitive speed. Ed 1: Jordan, a house from al-Muhaid to the Gulf for publication and distribution.

Abdullah,M. (2007). Scientific foundations in table tennis and measurement methods. Egypt, Zagazig.

Bloom,B. \& et al. (1983). Evaluate the student's formative and formative learning. Muhammad Amin AlMufti and others: Dar Al-Hikma McGr and Hill Publishing.

Farhat,L. (2002). Mathematical Cognitive Measurement. ed 1. Cairo: the Book Center for Publishing.

Fathalla,H. (2001). Setting standard levels for some physical abilities of tennis players. Master Thesis: Faculty of Physical Education for Boys, Alexandria University.

\footnotetext{
${ }^{4}$ Abdel-Hafez,T.(2016). attention control, working memory, and cognitive speed. Ed 1: Jordan, a house from al-Muhaid to the Gulf for publication and distribution.

${ }^{5}$ Hameed,A. \& Hamed,H.(2015). cognitive speed and intuition and levels of thinking. Ed 1.Jordan: the Arab community house.

${ }^{6}$ Abdullah,M.(2007). Scientific foundations in table tennis and measurement methods. Egypt, Zagazig.

${ }^{7}$ Hasanin,M.(1995). Methods of building and codifying tests and standards in physical education. Ed 2: The House of Arab Thought. 
Hameed,A. \& Hamed,H. (2015). Cognitive speed and intuition and levels of thinking. Ed 1.Jordan: the Arab community house.

Hasanin,M. (1995). Methods of building and codifying tests and standards in physical education. Ed 2: The House of Arab Thought.

Karajeh,A. (1997). Measurement and evaluation in psychology, a new vision: Dar Al-Bazouri Scientific Publishing and Distribution, Amman. 